\title{
Rahel Levin Varnhagen, die jüdischen Salons und die Nachtseite der Romantik
}

Auf ihrer Reise durch Deutschland begegnete Germaine de Staël selbstverständlich auch den großen Berliner „Salonières“, welche ähnlich wie sie selbst versuchten, eine Salonkultur des 18. Jahrhunderts in die neue Zeit hinüberzuretten und eine Männergesellschaft zu ,zivilisieren', welche ganz in den Antagonismen und Auseinandersetzungen einer postrevolutionären Zeit aufzugehen schien. Doch bereits wenige Jahre nach ihrem Besuch in Berlin hatten sich die Zeiten gewandelt. Niemals hätte sie sich vorstellen können, dass die wohl berühmteste unter allen Frauen, die in Deutschland jemals einen gesellschaftlich-literarischen Salon leiteten, an der nun eintretenden neuen Situation geradezu verzweifeln würde:

Bei meinem Teetisch ... sitze nur ich mit Wörterbüchern; Tee wird gar nicht mehr bei mir gemacht; so ist alles anders! Nie war ich so allein. Absolut. Nie so durchaus und bestimmt ennuyirt. Denn nur Geistreiches, Gütiges, Hoffnungsgebendes kann eine so Gekränkte, eine so Getötete noch hinhalten. Alles ist aber vorbei! Im Winter, und im Sommer auch noch, kannte ich einige Franzosen: Mit denen sprach ich hin und her, und wir sprachen das ab, was fremde gesittete, Literatur liebende und übende Menschen, die nicht eines Landes sind, absprechen und abstreiten können. Die sind alle weg. Meine deutschen Freunde, wie lange schon; wie gestorben, wie zerstreut! ${ }^{1}$

Eine Frau, nicht irgendeine Frau, befindet sich vor den Trümmern ihrer Existenz, ihres Lebens: Es ist keine andere als Rahel Levin alias Rahel Varnhagen. ${ }^{2}$ Sie sitzt an einem Teetisch in einer Wohnung, in der gar kein Tee mehr zubereitet wird, weil niemand mehr da ist, weil es kein Zusammenleben mehr gibt: keine Konvivialität und keine Konviven $z^{3}$ in einem sich ehedem stetig erweiternden Zirkel. Was war geschehen? Alle Freundinnen und Freunde, all ihre Gäste und Seelenverwandten waren gegangen, verschwunden, vom Winde verweht.

Wo einst das Gespräch, die gepflegte Konversation, der gesellige Austausch vorherrschten, sind nur noch Wörterbücher geblieben: Bücher, in denen jene Wörter aufbewahrt und aufgehoben sind, die einst in lebendigem Wechselspiel die Runde machten und eine ganze Gesellschaft erhellten. An die Stelle der Kon-

1 Varnhagen, Rahel: Brief an Gustav von Brinckmann (1808). In (dies.): Gesammelte Werke. Bd. I. München: Matthes \& Seitz 1983, S. 328.

2 Vgl. die als Habilitationsschrift vorgesehene Monographie der Philosophin Arendt, Hannah: Rahel Varnhagen. Lebensgeschichte einer deutschen Jüdin aus der Romantik. München - Zürich: Piper 1981.

$3 \mathrm{Zu}$ diesem Term vgl. Ette, Ottmar: Konvivenz. Literatur und Leben nach dem Paradies. Berlin: Kulturverlag Kadmos 2012. 
vivenz, des freudigen Zusammenlebens in einem von Soziabilität erfüllten Kreis, ist die Absenz getreten, eine Einsamkeit, die in ihrer Absolutheit auf der nicht mehr ganz jungen Frau lastet wie niemals zuvor. Konvivenz und Konvivialität haben einer gähnenden Leere, einer trauererfüllten Einsamkeit Platz gemacht: Alles ist vorbei! - Zumindest will es ihr so scheinen.

Rahel Levin sitzt also an einem verwaisten Teetisch in einem Raum, der von Bewegungen innerer wie äußerer Art erfüllt war und nun für immer menschenleer ist - und es auch bleiben wird. Bis vor kurzem noch war sie der umschwärmte Mittelpunkt einer Gesellschaft gewesen, die fröhlich und zuversichtlich in die Zukunft blickte. Doch selbst die wenigen Franzosen, mit denen sie noch in Kontakt stand, sind gegangen und haben sie allein zurückgelassen. Franzosen sind im damaligen Berlin nicht mehr beliebt!

Dabei handelt es sich um die (literarische) Nachhut jener Franzosen, die 1806 mit Napoleon in Berlin einmarschierten und der preußischen Gesellschaft der nachfriderizianischen Zeit im Zeichen von Toleranz und Offenheit, aber auch verkrusteter militärischer Hierarchien ein jähes Ende bereiteten. Preußen selbst schien mit all seinen Offizieren, mit all seinen Soldaten am Ende. Die Zeit Friedrichs des Großen war nun endgültig vorbei, der Geist von Sanssouci verweht, das preußische Rokoko mit seiner Heiterkeit entschwunden wie seine Soldaten und die Langen Kerls. Was war von Preußen noch geblieben?

Und die Franzosen? Nun sind auch sie weitergezogen, nach Osten wohl, ihrem eigenen Untergang entgegen, dem Untergang der Grande Armée, siegreich im Licht der brennenden Dörfer und Städtchen Russlands. Doch auch die Deutschen sind fort, sind entweder gefallen wie der Hohenzollern-Prinz Louis Ferdinand bei Saalfeld im Kampf gegen die Franzosen oder zwischen die Fronten von Preußen und Franzosen geraten wie Adelbert von Chamisso. Bisweilen haben sie es vorgezogen, beim Einmarsch Napoleons in Berlin lieber in Paris zu bleiben, wie der mit seinem Amerikanischen Reisewerk beschäftigte Alexander von Humboldt; oder sie sind schon bald mit der Reorganisation des preußischen Staates betraut wie sein älterer Bruder Wilhelm. Andere tragen sich mit dem Gedanken, den preußischen Staatsdienst zu quittieren und Königsberg wieder zu verlassen wie der bald in französische Kriegsgefangenschaft geratende Heinrich von Kleist oder der seiner zutiefst anti-französischen Haltung ergebene und sich an Österreich ausrichtende Friedrich von Gentz. Sie alle gehörten wie selbstverständlich dem Kreis an, der sich nur wenige Jahre zuvor um Rahel Levin geschart hatte, und der nun nicht mehr bestand.

Denn die Zeit der jüdischen Salons scheint ein für alle Mal vorbei. Die preuBische Gesellschaft musste sich neu finden und erfinden, bevor ein Neubeginn, der doch im Kern nicht Regeneration, sondern Restauration bedeutete, gemacht werden konnte. Im napoleonischen Wirbelsturm ordnen sich alle Figuren neu, 
bevor sich die reich mit Wappen bestickten Stühle des Wiener Kongresses endgültig zur neuen Ordnung der Monarchien formieren. Auch Wilhelm von Humboldt hatte hier seinen eigenen Stuhl: ${ }^{4}$ Preußen war schon bald wieder „on the map“.

Aber mit dem Einmarsch der französischen Armee in die preußische Hauptstadt waren die alte Gesellschaft Preußens und jene fröhliche der Rahel Levin gemeinsam und unwiederbringlich untergegangen. Auch jene Gesellschaft, die Madame de Staël einst kennengelernt hatte und die ihr etwas von jener Soziabilität vermittelte, die sie selbst so sehr liebte und pflegte. Nichts konnte sie mehr zurückbringen und zu neuem Leben erwecken! All das, wofür zwischen 1790 und 1806 der sogenannte Salon der Rahel Levin gestanden hatte, all das, was er noch nicht gesellschaftsfähig, aber doch zumindest salonfähig gemacht hatte - mithin die gezielte Überwindung ebenso nationaler wie religiöser, ebenso ,rassischer wie ständischer oder gesellschaftlicher Grenzen und Schranken - war ein für alle Mal dahin.

Atmosphäre und Logosphäre hatten sich gewandelt: Mit dem aufkommenden Franzosenhass gingen ein nie ausgerotteter Antisemitismus in Preußen und zugleich ein aufglühender Nationalismus einher; eine Kombinatorik, welche über anderthalb Jahrhunderte die Geschicke Preußens und Deutschlands bestimmen sollte und - wer weiß es schon - noch immer drohend am Horizont erscheint. Verschwörungstheorien zirkulierten - wie stets in Deutschland - mit ausgeprägt antisemitischen Untertönen. Die Welt ihres ureigenen Kreises, ihre DachstubenGesellschaft, war fast über Nacht für Rahel Levin zur „Welt von gestern“ geworden, zu einem plötzlich unerreichbaren Traum ${ }^{5}$ von einer Gemeinschaft, die sich in ihrer Tee-Gesellschaft über ein Jahrzehnt lang geradezu modellartig verwirklicht hatte. Was von diesem Traum blieb? Eine Frau sitzt 1808 vor den Trümmern ihrer Existenz. Aber auch ihres Lebens?

Die Philosophin Hannah Arendt hätte diese Frage sicherlich bejaht. Ihr Buch Rahel Varnhagen. Lebensgeschichte einer deutschen Jüdin aus der Romantik ${ }^{6}$ hatte sie im Jahr 1929 zeitgleich mit dem Abschluss ihrer Dissertation bei Karl Jaspers über den Liebesbegriff bei Augustinus in Angriff genommen. Bis auf zwei noch fehlende Kapitel stellte sie es bis zu ihrer Flucht aus Nazideutschland im Jahr 1933 fertig und schrieb die Schlusskapitel im französischen Exil nieder, bevor sie

4 Dieser Stuhl Wilhelm von Humboldts ist eines der Objekte der den Brüdern Humboldt gewidmeten Ausstellung, die aus Anlass des 250. Geburtstages Alexander von Humboldts von Bénédicte Savoy und David Blankenstein am Deutschen Historischen Museum kuratiert wird.

5 Vgl. zur Wichtigkeit des Traumes Hahn, Barbara: „Im Schlaf bin ich wacher.“ Die Träume der Rahel Levin Varnhagen. Frankfurt am Main: Luchterhand Literaturverlag 1990.

6 Vgl. Arendt, Hannah: Rahel Varnhagen. Lebensgeschichte einer deutschen Jüdin aus der Romantik. München - Zürich: Piper 1981. 
1957 zuerst eine englischsprachige, ${ }^{7}$ dann 1959 eine deutschsprachige Fassung erscheinen ließ. Von Beginn an stellte sie ihre Rahel ganz in das Licht des Judentums. Was uns heute selbstverständlich erscheint, war ein Jahrhundert nach Rahels Tod durchaus innovativ.

Gleich mit ihrem Incipit machte Arendt deutlich, dass Rahel Teil einer Geschichte war, die weit über sie hinausging, wodurch die Philosophin auch ihre eigene Lebensgeschichte besser verstand:

\begin{abstract}
„Welche Geschichte! - Eine aus Ägypten und Palästina Geflüchtete bin ich hier und finde Hilfe, Liebe und Pflege von Euch! ... Mit erhabenem Entzücken denk' ich an diesen meinen Ursprung und diesen ganzen Zusammenhang des Geschickes, durch welches die ältesten Erinnerungen des Menschengeschlechts mit der neuesten Lage der Dinge, die weitesten Zeit- und Raumfernen verbunden sind. Was so lange Zeit meines Lebens mir die größte Schmach, das herbste Leid und Unglück war, eine Jüdin geboren zu sein, um keinen Preis möcht' ich das jetzt missen. “So berichtet Varnhagen von Rahels Totenbett. Dreiundsechzig Jahre hat sie gebraucht zu lernen, was 1700 Jahre vor ihrer Geburt begann, zur Zeit ihres Lebens eine entscheidende Wendung und hundert Jahre nach ihrem Tode - sie starb am 7. März 1833 - ein vorläufiges Ende nahm.

Schwer mag es sein, seine eigene Geschichte zu kennen, wenn man 1771 in Berlin geboren wird und diese Geschichte schon 1700 Jahre früher in Jerusalem beginnt. Kennt man sie nicht, und ist man auch nicht geradezu ein Lump, der jederzeit Gegebenes anerkennt, Widriges umlügt und Gutes vergißt, so rächt sie sich und wird in ihrer ganzen Erhabenheit zum persönlichen Schicksal, was für den Betroffenen kein Vergnügen ist. ${ }^{8}$
\end{abstract}

Hannah Arendt stellt in ihrer einflussreichen, ja die Rezeptionsgeschichte der von ihr Portraitierten bis heute prägenden Biographie Rahel in den größeren Zusammenhang einer Geschichte des Judentums, dem die in Königsberg geborene Philosophin selbst auch angehörte. Letztere schloss ihre ursprünglich als Habilitationsschrift gedachte Studie hundert Jahre nach Rahels Tod vorläufig ab und versah sie mit einer Vielzahl an autobiographischen Fenstern, welche ihre Biographie kunstvoll als Autobiographie zu einem verdoppelten Überlebenschreiben werden ließen. ${ }^{9}$ Genauso verstand sie Rahel wie auch sich selbst vor dem Hintergrund

7 Mir liegt vor: Arendt, Hannah: Rahel Varnhagen. The Life of a Jewess. First complete edition. Edited by Liliane Weissberg. Translated by Richard and Clara Winston. Baltimore - London: The Johns Hopkins University Press 1997.

8 Arendt, Hannah: Rahel Varnhagen. Lebensgeschichte einer deutschen Jüdin aus der Romantik, S. 15.

9 Vgl. das Hannah Arendts Buch über Rahel Varnhagen gewidmete sechste Kapitel „Auswanderung. Leben über Leben: Überlebenswissen aus der Verdoppelung“ in Ette, Ottmar: ÜberLebenswissen. Die Aufgabe der Philologie. Berlin: Kulturverlag Kadmos 2004, S. 171-188; sowie Sánchez, Cecilia: Sobrevivir: transiciones del cuerpo mortal e inmortal en Hannah Arendt. In: Vatter, Miguel / Nitschack, Horst (Hg.): Hannah Arendt: sobrevivir al totalitarismo. Santiago de Chile: LOM Ediciones 2008, S. 77-88. 
einer jüdischen Geschichte und eines jüdischen Schicksals, von dem es in der letzten Kapitelüberschrift heißt: „Aus dem Judentum kommt man nicht heraus. “10 Diese Überschrift bezieht sich auf Rahel Varnhagen, ist zugleich aber auch auf Hannah Arendt und ihr diskursives Handeln ${ }^{11}$ selbst gemünzt. Hinter dem Leben der einen Jüdin ist immer auch das Leben der anderen Jüdin zu erkennen: Beide teilen sie ein Schicksal, das ihrem Leben Sinn gibt und Sinn macht; ein jeweils verdoppeltes Leben, eingeschrieben in die lange Geschichte des Judentums.

Dabei ist auffällig, dass es Hannah Arendt ${ }^{12}$ nicht um die „condition féminine“, nicht um die Weiblichkeit und mehr noch ihre spezifische Situation und Marginalisierung als Frau geht, ${ }^{13}$ sondern allein die ,condition juive“ im Mittelpunkt der Aufmerksamkeit steht. Aus dieser Perspektive ist das abrupte Ende des Rahel'schen Salons auch gleichbedeutend mit dem Sturz von einem Gipfel, den die „deutsche Jüdin aus der Romantik“ im Sinne Hannah Arendts in ihrem Leben nie wieder erreichen konnte. Aus dieser Blickrichtung musste auch alles, was mit Karl August Varnhagen von Ense, mit seiner aufopferungsvollen Bewunderung, seiner Vermählung mit Rahel und selbst noch mit seiner Pflege ihres Nachlasses und ihrer Schriften zu tun hatte, im Zeichen eines Abstieges, eines Unverständnisses, ja eines Nicht-Begreifen-Könnens stehen, dessen sie Varnhagen mit nachhaltigen Folgen bezichtigte. Denn der erst nach der Hochzeit nachträglich nobilitierte Varnhagen wurde zu so etwas wie dem dummen Trottel in der jüdischen Lebensgeschichte Rahels stilisiert. Wenn Sie es mir erlauben: Hier irrte die große Frau!

War nicht Karl August Varnhagen von Ense just in jenem Jahr 1808, in dem wir Rahel Levin vor den Trümmern ihrer Existenz gesehen hatten, mit seiner Bewunderung und Liebe am Horizont ihres Lebens und Schreibens aufgetaucht? Hatte er ihr nicht nach ihrer Konvertierung zum Christentum die Vermählung offeriert und schließlich auch die Möglichkeit geboten, in Berlin ihren zweiten Salon zu eröffnen, um damit die Fäden ihres Lebens weiterzuspinnen, kurz: zu jener Rahel

10 Arendt, Hannah: Rahel Varnhagen, S. 201.

11 Vgl. hierzu Lobo, María Fátima: Hannah Arendt y la pregunta por la relación entre el pensamiento y la acción. Buenos Aires: Editorial Biblos 2013.

12 Vgl. allgemein Brunkhorst, Hauke: Hannah Arendt. München: Beck 1999.

13 Vgl. zur Kritik an dieser „Leerstelle“ Arendts insbesondere Maslin, Kimberly: Rahel Varnhagen: Arendt's Experiential Ontology. In: New German Critique (Durham) XL, 119 (Summer 2013), S. 77-96; sowie aus anderer Perspektive Benhabib, Seyla: The Pariah and Her Shadow: Hannah Arendt's Biography of Rahel Varnhagen. In: Honig, Bonnie (Hg.): Feminist Interpretations of Hannah Arendt. University Park: The Pennsylvania State University Press 1995, S. 83-104; sowie (dies.): The Pariah and Her Shadow: Hannah Arendt's Biography of Rahel Varnhagen. In: Political Theory XXIII, 1 (February 1995), S. 5-24. 
Varnhagen zu werden, wie Hannah Arendt sie selbst zu nennen pflegte? Entsteht so nicht erst jene komplexe Figur einer Rahel Levin Varnhagen, deren schillernde Widersprüchlichkeit sich erst in vollem Maße entwickeln kann?

Nein! Im Jahre 1808 war längst noch nicht alles vorbei, sondern es bildeten sich vielmehr Bedingungen heraus, welche Rahel erst zu dem werden ließen, was sich dem „Andenken für ihre Freunde“ eröffnete und sie zu einer großen Figur der deutschsprachigen Literatur wie der deutschen Romantik überhaupt machte.

Rahel Levin war in Berlin 1771 in eine wohlhabende jüdische Kaufmanns- und Bankiersfamilie als ältestes Kind hineingeboren worden und wuchs in behüteten Verhältnissen auf. Ihr Vater Markus Levin war als Juwelierhändler in Geldgeschäften geschickt und wachte als Patriarch zwar streng über die Geschicke seiner Frau Chaie wie seiner Familie, aber stets in einem Rahmen, in dem Geselligkeit und Konvivialität ein hoher Stellenwert zukam. Die Kinder waren an ein Haus voller Gäste und vieler Gespräche gewöhnt: Soziabilität war ein hohes Gut, das auch die junge Rahel zu bewahren suchte.

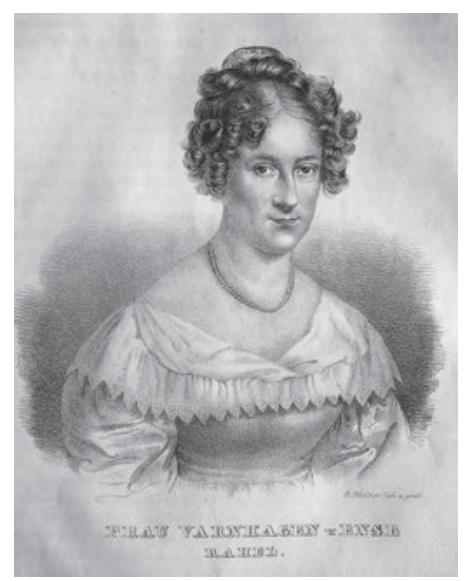

Abb. 45: Rahel Varnhagen von Ense, geborene Levin (Berlin, 1771 - ebenda, 1833).

Nach dem plötzlichen Tod ihres Vaters im Jahr 1790, der Übernahme der Geschäfte durch die männlichen Nachkommen und der raschen Regelung aller finanziellen Fragen entstand noch im selben Jahr in der Berliner Jägerstraße ein erster literarischer Salon. Dessen Mittelpunkt bildete die junge, zwar nach Bekunden der Zeitgenossen nicht sehr hübsche, aber ungeheuer auffassungsschnelle und geistreiche Rahel Levin. Es handelte sich um einen jener Salons, die sich auch um andere Frauen jüdischer Abstammung wie Henriette Herz ${ }^{14}$ oder Dorothea

14 Vgl. Arendt, Hannah: Rahel Varnhagen, S. 39 f. 
Schlegel gebildet hatten und für jene intellektuelle Offenheit einstanden, die für das Berlin des ausgehenden 18. Jahrhunderts so charakteristisch war. In ihnen herrschte ein freier Geist, der auch die traditionellen Geschlechterrollen erfasst hatte. Gerade für die Jüdinnen bot sich hier die Chance, mit anderen Lebensentwürfen und Lebenspraktiken zu experimentieren. Wir können diesem Experiment in unserer Vorlesung freilich nicht weiter folgen und werden den ersten Salon der Rahel Levin in unserer Vorlesung zur Aufklärung und zum 18. Jahrhundert zwischen zwei Welten behandeln; ein Salon, in welchem sich die Brüder Schlegel wie die Brüder Humboldt, Adelbert von Chamisso wie Johann Gottlieb Fichte ein Stelldichein gaben. Hier aber konzentrieren wir uns auf die romantische Rahel oder eine Rahel im Zeichen einer Romantik, die in Deutschland sehr spezifische Züge trug.

Einen Wendepunkt in ihrem Leben bedeutete eben jenes Jahr 1808, an dem wir sie eingangs weinend an ihrem Teetisch getroffen hatten. Denn in diesem Jahr lernte sie Varnhagen erstmals näher kennen. ${ }^{15}$ Es war für Rahel keine Liebe auf den ersten Blick. Von Varnhagens Seite hingegen bestand sehr bald schon eine Leidenschaft für sie, die aber wiederum in Liebesdingen mittlerweile vorsichtiger geworden war und zunächst abwartend reagierte. Am 12. Mai 1808 beginnt ihr Briefwechsel, der bereits die ganze Spannbreite der Beziehung bis zu ihrem Tode auszuleuchten unternahm. In einer Zeit, in welcher sich Rahel von ihrer Mutter und der berühmten Wohnung in der Jägerstraße und damit von der berühmten ,Dachstube‘ ihres Salons trennen musste, entspann sich dann jedoch ein Band zwischen den beiden, das ungeachtet einiger Wirren und Zerwürfnisse nicht mehr abreißen sollte. Gewiss ist seit Hannah Arendt viel über diese Beziehung geschrieben worden; und in aller Regel war es der jüngere Varnhagen, der stets in allen Vergleichen sehr schlecht wegkam. Als Beispiel hierfür sei nur kurz die Ansicht eines Herausgebers der Briefe Rahel Levin Varnhagens erwähnt, der das Paar mit den folgenden Worten beschrieb: „Dennoch, es war nicht zu übersehen: allzu ungleich waren die Gaben verteilt; aller Glanz ging von ihr aus, er war nicht viel mehr als ein bewundernder Spiegel.“16

Friedhelm Kemp merkt zwar zurecht an, dass Hannah Arendt „Rahels Judentum als ein zentrales Thema ihres Lebens erörtert"17 und treffend festhält, der Band sei ,auf eine sehr eigenwillige Weise, und eben deshalb, das Bedeutend-

15 Vgl. Danzer, Gerhard: Rahel Varnhagen - eine Frau entdeckt sich über die Kultur. In: Pilz, Elke (Hg.): Bedeutende Frauen des 18. Jahrhunderts: elf biographische Essays, S. 157-172, insb. S. 161. 16 Kemp, Friedhelm: Nachwort. In: Varnhagen, Rahel: Briefwechsel. Band II. München: Winkler Verlag 1979, S. 401.

17 Ebda., S. 403. 
ste, Selbständigste und Eindringlichste, das bis heute über die Rahel geschrieben wurde“ “ ${ }^{18}$ Doch wird auch bei ihm die Figur des Varnhagen von Ense auf den Spuren Arendts förmlich weggewischt, ja erscheint nur noch als bloßer Reflektor eines Lichts, das nicht seines war. Aber darf man nicht vermuten, dass Hannah Arendt diesen Varnhagen von Ense in den Hintergrund drängen wollte, weil er sich nicht in die jüdische Geschichte der Rahel einbauen ließ?

Wie dem auch immer sein mag: Karl August Varnhagen von Ense hielt zu Rahel Levin - auch und gerade in ihren schwersten Monaten und Jahren! Im Deutschland jener Zeit lebte Rahel Levin als Jüdin auf der Schattenseite der Gesellschaft, auf der Schattenseite der deutschen Romantik. Varnhagen aber wurde zum ersten Herausgeber ihrer Briefe und schuf damit die Grundlage, die uns noch heute dazu dient, die ganze Größe und Bedeutung der Rahel Levin Varnhagen jenseits ihrer Tätigkeit als Zentrum eines Salons, als Salonière zu erkennen. Und dieser Mann soll nichts, rein gar nichts von ihr verstanden haben? Nichts als ein geschwätziger Begleiter soll er gewesen sein, oder gar ein stummer Spiegel?

Varnhagen von Ense dient sich im Juni 1809 der österreichischen Armee unmittelbar nach deren Sieg unter Erzherzog Karl im Mai über Napoleon an. Er hofft aus gutem Grund sowie letztlich erfolgreich, damit eine bessere Grundlage für sein Leben legen und in die Diplomatie aufsteigen zu können. Damit beginnt recht bald schon eine unstete Zeit der Reisen und Ortswechsel, welche aber auf Dauer die Beziehung zu Rahel nicht zu erschüttern vermag. So verbringt das Paar etwa den Sommer 1811 gemeinsam in Teplitz und erweitert seinen Bekanntenund Freundeskreis beständig, so dass sich schon bald ein weiteres Beziehungsgeflecht herausbildet, welches das Netzwerk der Korrespondenten weiter nährt.

Der österreichische Offizier Varnhagen von Ense knüpft klug an seinen Beziehungen an und stellt geschickt Verbindungen mit Preußen her, die ihm noch einmal nützlich werden sollten. Aber noch ist alles prekär, alles scheint an einem seidenen Faden zu hängen: die Zukunft, die Politik, das persönliche Glück, die Freundinnen und Freunde, ja das Leben und Überleben in Kriegszeiten selbst. Rahel schreibt am 16. September 1811 aus Dresden an Varnhagen von Ense:

Höre zum Troste, dass ich mich weit mehr über das Getrenntsein von Dir gräme, als ich's je gedacht hätte. Auch mir ist ganz ängstlich: ich fühle mich plötzlich so abgerissen, von Schutz, Sicherheit, und Liebe, dass ich rund um mich herumgehen könnte, um nur zu sehen, um nur zu finden: zu wem gehörst Du denn? zu was? Gestern machte ich gegen Abend den herrlichsten Gang mit Marwitz und Lippe, wohl eine Meile, die Ostrawiese hinauf. Du weißt, ob und wie ich Marwitz liebe, es waren zwei Freunde: wir gingen manchmal still, groß und göttlich war der weite Raum, die prachtvolle Sonne und Abendröte, die

18 Ebda. 
ernsten und ganz anderen Bäume als in Böhmen, die unendlichen Alleen; allein ich mußte denken: Allein und fremd bist du hier, wenn diese beiden nicht mitgehen wollen; allein und fremd, wenn sie auch neben dir bleiben; du bist nicht ihr Liebstes, sie beziehen nicht alles auf dich. Wie gewiß lebt' ich bisher! Und ich war nicht undankbar, Varnhagen! nimm es nicht so roh, wie das Wort hier dasteht: es war nicht nur Dankbarkeit, es war liebende Sehnsucht; und mein Herzenssehnen antwortete Deinem, mein Herz hielt Takt mit Deinem. Und so sind meine meisten Momente. ${ }^{19}$

In einer Zeit und einem Kontext der Unsicherheit, in einer Epoche großer Umwälzungen und unabsehbarer Veränderungen konstatiert Rahel den fehlenden Schutz, die fehlende Sicherheit, um in der Präsenz neuer Freunde doch die Absenz des ihr fehlenden Varnhagen anzurufen. Wir sehen in diesem Schreiben eine Rahel, die sich aller Topoi des romantischen Briefs bedient, die eine am Herzen und an der dort verorteten Sehnsucht ausgerichtete liebende Beziehung beschwört, in welcher auch ein intensiver Blick auf eine romantisch in Szene gesetzte Landschaft nicht fehlen darf. Es ist zugleich ein Hilferuf der Einsamkeit. Varnhagen von Ense aber war jederzeit bestrebt, Rahel eben jene Gewissheit und Sicherheit zu geben, derer sie bedurfte, um sich nicht verlassen zu fühlen.

Zugleich bemüht er sich um Rahels literarisches Werk, bittet er 1811 doch erfolgreich Goethe, Auszüge aus seinem Briefwechsel mit Rahel Levin zur Veröffentlichung zu bringen: Die Korrespondenz erscheint 1812 in Cottas Morgenblatt - die meines Wissens erste Herausgeberschaft des jungen Varnhagen, die Korrespondenz Rahels betreffend. Damit war zugleich nicht nur der Bewunderung von Rahel Levin für Goethe Ausdruck gegeben, sondern die Grundlage gelegt für jenen überschwänglichen Goethe-Kult, der von Rahels zweitem, romantischen Salon ausgehen sollte.

In den Wirren der napoleonischen Kriege sieht sich das Paar nur selten, verbringt nach der Völkerschlacht bei Leipzig und der Niederlage Napoleons aber den darauf folgenden Sommer des Jahres 1814 gemeinsam wiederum in Teplitz. Fast ein Jahrzehnt lang reist Rahel immer wieder ihrem Liebhaber in verschiedenste Städte Europas nach und folgt ihm schließlich nach Wien, wo er in Diensten Hardenbergs am Wiener Kongress teilnimmt. Die Zeit der Reisen, des Abschieds und des Wiedersehens neigt sich noch nicht ihrem Ende zu, denn nach wie vor herrscht über Europa der napoleonische Sturm, der erst abflauen musste. Wie Germaine de Staël befindet sich auch Rahel Levin in einer mobilen Wartestellung, der historischen Dinge harrend, die sich schon bald ereignen sollten.

19 Varnhagen, Rahel: Brief an Varnhagen von Ense vom 16. September 1811. In (dies.): Briefwechsel, Bd. 2, S. 166. 
Im September 1814 konvertiert Rahel Levin zum Christentum und nimmt die Taufnamen Antonie Friederike an; die Vermählung mit Karl August Varnhagen folgt auf dem Fuße. Zwei Wochen zuvor, am 13. September 1814, schickt sie an ihren Varnhagen folgende Worte:

Goldener August, wie kann ich Deinen liebevollen feinen Brief beantworten, als mit mir selbst, als mit dem Anerkennen, was Du bist [...]. Bei mir zeigt sich mein Rechttun in Deiner Person: aber dass Du recht habest, ist schwer zu sehen. Heute morgen lag das Sophakissen in meinem Bette, welches Du in Teplitz gebrauchtest. Es erregte mein ganzes Herz mit seinem Riß, den es von Dir hat! Nun aber kein zärtlich Wort mehr! Denn - außer der Zeit kann man nichts tun ... ${ }^{20}$

Wieder ist das Herz der Sitz aller zärtlichen Gefühle. Auch hier sehen wir wieder eine Rahel als Briefeschreiberin, die ihren Briefpartner antippt, ihm einen Impuls gibt, ohne doch selbst alles zu sagen und zu kommentieren. Der Brief gibt einen guten Eindruck vom Ton, der zwischen beiden herrscht, ohne doch jeweils zu viel preiszugeben - ganz so, als wäre auch dieser Brief von Anfang an so konzipiert, als dass er mühelos veröffentlicht werden könnte. Nein, es ist kein Brief einer ostentativen Romantik, auch wenn er alle Zeichen einer sich im materiellen Detail des Kissens verkörpernden romantischen Liebe trägt!

Das Glück hält Einzug, als Varnhagen im Juli 1816 zum preußischen Geschäftsträger am badischen Hofe in Karlsruhe ernannt wird. Für Rahel Varnhagen sind es - nach langen Jahren des Reisens, des Wiedersehens und der erneuten Trennung von Varnhagen - nach eigenem Bekunden die glücklichsten Jahre, die sie in der badischen Residenzstadt verbringen darf. Napoleon ist für sie Geschichte, ganz so wie Germaine de Staël endgültig ihren politischen Gegenspieler verloren hatte. Im Oktober 1819 aber ist für Rahel diese Zeit am badischen Hofe zu Ende. Varnhagen wird ohne Angabe von Gründen abberufen: Man zieht gemeinsam zurück nach Berlin.

Karl August Varnhagen, der bald schon seinen Adelstitel von Ense anerkennen lässt, entwickelt sich nach seiner Abberufung als preußischer Geschäftsträger in Karlsruhe zu jenem Publizisten, Geschichtsschreiber und Sammler, als der er uns heute wohl überwiegend bekannt ist. Berühmt wurde er später auch durch seinen Briefwechsel mit Alexander von Humboldt, den Rahels Nichte Ludmilla Assing $^{21}$ kurz nach Alexander von Humboldts Tod veröffentlichte - nicht ohne

20 Varnhagen, Rahel: Brief an Varnhagen vom 13. September 1814. In (dies.): Briefwechsel, Bd. 2, S. $295 \mathrm{f}$.

21 Vgl. hierzu Briefe von Alexander von Humboldt an Varnhagen von Ense aus den Jahren 1827 bis 1858. Nebst Auszügen aus Varnhagen's Tagebüchern, und Briefen von Varnhagen und anderen an Humboldt. Herausgegeben von Ludmilla Assing. Leipzig: F.A. Brockhaus 1860. 
damit dem postumen Bild Alexanders Schaden zuzufügen, da man von ihm eine solche Offenheit und Kritik am preußischen Königshof nicht erwartet hatte. Doch im Grunde war die Freimütigkeit, mit der Alexander von Humboldt Karl August Varnhagen von Ense in seine wissenschaftlichen und literarischen, aber auch in seine politischen Überzeugungen Einblick gewährte, Beweis genug für die Wertschätzung, die dem Ehemann von Rahel zumindest in den liberalen Kreisen der preußischen Gesellschaft zuteilwurde. Wenn es eines Beweises in die Vertrauenswürdigkeit Varnhagens noch bedurft hätte, Alexander von Humboldt liefert ihn. Die Briefe vermitteln ein gutes Bild beider Persönlichkeiten und ihres kritischen Verhältnisses gegenüber jenen Zeitläuften, gegen die sich Humboldt mehr als ein halbes Leben lang stemmte. Varnhagen war ihm hierbei ein wichtiger Gesprächspartner.

Schon bald bezog das Ehepaar Varnhagen eine geräumige Wohnung unweit von Rahels ursprünglichem Wirkungskreise. Das schriftliche Netzwerk der vielen Freundinnen und Freunde, Vertrauten und Weggefährten bestand noch immer und diente Rahel als Anknüpfungspunkt. Bald schon konnte Antonie Friederike Varnhagen von Ense, die freilich allen auch weiterhin als Rahel bekannt war, erneut einen illustren Kreis um sich scharen, den man gemeinhin als ihren „zweiten Salon“ bezeichnet. Es ist - Hannah Arendt paraphrasierend - der Salon einer großen Jüdin aus der deutschen Romantik.

Auch dieser zweite Zirkel vereinigte in einem veränderten politischen Umfeld der Restauration Mitglieder unterschiedlicher Stände, Wissenschaftler verschiedenster Herkunft, jüdische Schriftsteller und Gelehrte zu einem Kreis, der sich um die Figur der Rahel Varnhagen schloss. Denn sie - und nicht etwa ihr Ehemann Varnhagen - bildete das unbestrittene Zentrum ihrer Gesellschaft, ihres Salons: Ihr Mann hielt sich im Hintergrund und überließ die Bühne seiner erfahrenen Frau, die es verstand, Adlige und Bürgerliche, Juden und Christen unter veränderten gesellschaftlichen Bedingungen gleichermaßen anzuziehen.

Ihre Gemeinschaft wurde wieder zu einem Hort des freien Wortes in einer Gesellschaft, die nach Wiener Kongress und Karlsbader Beschlüssen zunehmend repressiv geworden war. Andere Zirkel gaben nun den Ton an: etwa die von Clemens Brentano mitbegründete Christlich-Deutsche Tischgesellschaft, die über feste Statuten verfügte und allein Männern vorbehalten war. ${ }^{22}$ Aus vielen Zirkeln waren Juden, aber auch Franzosen ausgeschlossen. Die Salonière bildete in einem zunehmend nationalistisch denkenden Deutschland - anders als in Frankreich eher die Ausnahme: Französische und deutsche Soziabilität drifteten stärker auseinander.

22 Vgl. Arendt, Hannah: Rahel Varnhagen, S. 86 und $119 \mathrm{f}$. 
In Kontrast zu derartigen Zirkeln nationalistischer Romantiker ließen sich auch mit Blick auf Rahels zweiten Kreis wiederum mancherlei Zelebritäten anführen, die ihren Salon bevölkerten und ihm eine beeindruckende Lebendigkeit und Offenheit verliehen. Zum Kreis von Rahels Gästen zählten etwa Fürst Hermann von Pückler-Muskau oder Alexander und Wilhelm von Humboldt, Leopold von Ranke oder verschiedene Mitglieder der Familie Mendelssohn, Eduard Gans oder Adelbert von Chamisso, Hegel, Fichte oder Schleiermacher, die Schriftsteller Heinrich Heine oder Ludwig Börne, Autoren, für die sich Rahel nachdrücklich einsetzte. Es war faszinierend, welche unterschiedlichen Geistesgrößen sie anzuziehen verstand!

Aber das politische Umfeld hatte sich verändert: Clemens Brentanos Zirkel mag hier beispielgebend sein, verbannte er aus seinem Kreis doch nicht nur alle Franzosen, sondern auch die Frauen, die Philister und vor allem die Juden. Seine Christlich-Deutsche Tischgesellschaft propagierte offen antijüdische und gewiss auch antisemitische Tendenzen, an denen sich Brentano selbst durchaus aktiv beteiligte. Das Modell für eine künftige Gesellschaft war hier offen restriktiv und restaurativ; es stand in einem klaren Gegensatz zur Konvivialität und Konvivenz jener Gemeinschaft, die sich um Rahel Varnhagen scharte. Diese Gemeinschaft aber war nun überdeutlich minoritär. Neben künstlerischen, literarischen und philosophischen Gegenstandsbereichen dominierten nun neben dem wichtigen Goethe-Kult in Rahels zweitem Salon die politischen Themen, wobei gesellschaftsutopische und speziell saint-simonistische Vorstellungen von großer Bedeutung waren. Rahel Varnhagen verstand es elegant, die nunmehr stärker politische Ausrichtung ihres Salons in ein Mobile der Möglichkeiten zu übersetzen, das in einer kleinen Gesellschaft gleichzeitig Modell und lebbare, ja im wahrsten Sinne gelebte Wirklichkeit werden sollte. Diese prospektive Dimension des zweiten Salons darf man auf keinen Fall unterschätzen!

In all ihren Aktivitäten wurde Rahel Levin Varnhagen nunmehr von ihrem Ehemann tatkräftig unterstützt. Gewiss besaß er nicht die literarische und künstlerische Strahlkraft, die für seine Frau so bezeichnend war; doch war er immer wieder bemüht, sich positiv ebenso in ihr Netzwerk in Form mündlicher Dialoge und Gespräche einzubringen wie auch ihr sich stetig vergrößerndes literarisches Netzwerk zu befördern. Mit nicht wenigen der Salonbesucher führte er seinerseits eine interessante Korrespondenz und erlangte einen Überblick über die Entwicklungen in Preußen, der sich auch in dem Vierteljahrhundert nach Rahels Tod im Jahr 1833 bis zu seinem Tod im Jahre 1858 beständig erweiterte. Rahel Levin Varnhagen war ohne Varnhagen nicht mehr zu denken.

Aber auch Varnhagen nicht ohne Rahel: Die tiefe Trauer über das frühe Ableben seiner Frau zeigt sich rasch in seiner Korrespondenz, wich aber bald einem konkreten Bemühen, das Andenken der Rahel zu ehren und ihr einen Platz 
in der literarischen (und auch politischen) Welt Preußens zu verschaffen und zu sichern. Bereits wenige Monate nach dem Tod der Rahel Levin Varnhagen gab ihr Ehemann eine (noch im Einverständnis mit ihr) zusammengestellte Sammlung heraus, deren Bedeutung schlicht nicht überschätzt werden kann: Rahel. Ein Buch des Andenkens für ihre Freunde. ${ }^{23}$

Diese zunächst in einem einzigen und nachfolgend für den Buchhandel in drei Bänden herausgebrachte Sammlung bildet gleichsam den Ursprung all jener Editionen und Herausgeberschaften, die bis heute immer wieder die verschiedenen Phasen der Rezeption Rahel Levin Varnhagens begleiten. ${ }^{24}$ Es war, wie schon erwähnt, nur eine weitere in Varnhagens Herausgeberschaften von Rahel Levin Varnhagens Briefen; aber sie war als monographisches Werk doch bahnbrechend und zukunftsweisend, adressierte diese Sammlung doch die unmittelbaren Freunde, griff aber bewusst weit über den Freundeskreis auf ein allgemeines Publikum aus. Sie wurde als literarisches Denkmal zur Keimzelle jener Entwicklung, die post mortem Rahel ihren Status als große deutschsprachige Schriftstellerin verlieh. Dies wäre ohne die geduldig sammelnde und herausgeberische Aktivität Varnhagens nicht denkbar gewesen.

Allgemein wird berichtet, dass zu Beginn der 1830er Jahre ebenso die Salongäste wie die Brieffreunde das langsame Schwinden von Rahels Kräften bemerkten. Man vermeinte zu spüren, dass sie nicht mehr mit aller Energie und Intensität bei der Sache war, dass sie leicht kränkelte und bettlägerig wurde. Doch am 1. Februar 1833, also kaum mehr als einen Monat vor ihrem Tod, schrieb ihr Alexander von Humboldt kurioserweise ganz in Sorge nicht um sie, sondern um Varnhagen von Ense. Seine Wortwahl im Brief an Rahel ist dabei bemerkenswert: „Möchten Sie mir doch ein tröstendes Wort über den theuren Varnhagen sagen, die einzige glänzende Stütze unserer Litteratur (im edleren Sinne des Wortes) unseres Vaterlandes“. ${ }^{25}$ In derlei Formulierungen kommt zum Ausdruck, wie sehr Humboldt Rahels Ehemann zu schätzen wusste und wie wenig er ihr eigenes

23 Varnhagen von Ense, Karl August (Hg.): Rahel. Ein Buch des Andenkens für ihre Freunde. 3 Bände. Berlin 1834; mir liegt die folgende Ausgabe vor: Rahel. Ein Buch des Andenkens für ihre Freunde. Berlin: Matthes \& Seitz 2010.

24 Vgl. zur frühen Rezeptionsgeschichte u. a. Volkening, Heide: Die Philologin, Rahel Varnhagen und das allgemein Menschliche. Varnhagen-Studien im ersten Drittel des 20. Jahrhunderts. In: Kauko, Miriam / Mieszkowski, Sylvia / Tischel, Alexandra (Hg.): Gendered Academia. Wissenschaft und Geschlechterdifferenz 1890-1945. Göttingen: Wallstein Verlag 2005, S. 237-253; sowie Whittle, Ruth: Gender, Canon and Literary History. The Changing Place of Nineteenth-Century German Women Writers, S. 64-84.

25 Humboldt, Alexander von: Brief an Rahel vom 1. Februar 1833. In: Briefe von Alexander von Humboldt an Varnhagen von Ense, S. 12. 
baldiges Sterben in Betracht zog. Doch fünf Wochen später erfuhr Alexander von Humboldt vom Tod der Rahel und wandte sich in einem Brief vom 9. März desselben Jahres an den um sie trauernden Varnhagen: „Sie wissen, welche warme, langgeprüfte, nachsichtsvolle Freundin ich an Ihr, der Zierde ihres Geschlechts, verliere [...].“26

So wie Humboldt reagierten viele von Rahels Freundinnen und Freunden. Das von Varnhagen edierte Buch des Andenkens für ihre Freunde war durchaus für Mitglieder ihres Zirkels, ihres Salons bestimmt; doch es schuf die Grundlage für eine postume Kanonisierung und Rahels bis heute anhaltenden Aufstieg zu einer Zentralfigur der deutschen Literatur der Romantik. Mit der getroffenen Auswahl an Briefen und Tagebucheinträgen generierte es im eigentlichen Sinne das literarische Werk der Rahel Levin Varnhagen, indem es ihr Schreiben in die Reichweite einer breiten Öffentlichkeit im deutschsprachigen Raum rückte. Gewiss, es brauchte Zeit, bis die eigentliche Bedeutung der Rahel Levin Varnhagen als Jüdin und weibliche Schriftstellerin, als Kämpferin für die Emanzipation der Juden wie für die Emanzipation der Frauen verstanden werden konnte! Es ist dieser doppelte Grund, warum unsere Vorlesung nicht auf Rahel verzichten kann.

Nicht nur ihr mündliches, polylogisches Werk, sondern auch ihre schriftlichen Schöpfungen standen nun vor aller Augen und bezeugten eine Schriftstellerin, die sich ihrer doppelt marginalisierten Rolle als Jüdin und Frau sehr wohl bewusst war und mit ihren Gesprächs- wie mit ihren Korrespondenzpartnern offen für eine doppelte Gleichstellung - die der Juden und die der Frauen - im damaligen Preußen eintrat. Wenige Jahre später urteilte Heinrich Heine in seinem Buch der Lieder - eine offensichtliche Titelhommage an Rahels Andenken - in folgender Weise: „Es ist, als ob Rahel wusste, welche posthume Sendung ihr beschieden war. Sie glaubte freilich, es würde besser werden, und wartete; doch als des Wartens kein Ende nahm, schüttelte sie ungeduldig den Kopf, sah Varnhagen an, und starb schnell - um desto schneller auferstehen zu können. “27 Der große jüdische Dichter der deutschen Romantik erkannte sehr scharf, dass Rahels literarisches Werk seine Zukunft noch vor sich hatte, dass ihre „Sendung“ keineswegs zu Ende war; denn Rahel Levin Varnhagens Wirkung entfaltete sich weit über ihren Tod hinaus.

26 Humboldt, Alexander von: Brief an Varnhagen von Ense vom 9. März 1833. In: Briefe Alexander von Humboldts an Varnhagen von Ense, S. 16.

27 Heine, Heinrich: Vorrede zum Buch der Lieder (1837). In (ders.): Sämtliche Schriften. Herausgegeben von Klaus Briegeleb. Bd. 1. München: Carl Hanser Verlag 1968, S. 10. Vgl. hierzu Danzer, Gerhard: Rahel Varnhagen - eine Frau entdeckt sich über die Kultur, S. 165. 
Betrachtet man ihr Leben in seiner Gänze, so steht es deutlich im Zeichen einer Soziabilität, die gewiss von ihrem Vater auf sie übergegangen war. ${ }^{28} \mathrm{Ihr}$ gesamtes Leben schreibt sich ein in die Herausbildung neuer Formen dieser Soziabilität, ${ }^{29}$ der Freundschaft und Intimität sowie einer Konvivialität, wie sie sich in neuen Umgangsformen an der Wende zum 19. Jahrhundert in Preußen und Deutschland etablierten. Dabei war es gerade für jüdische Frauen und deren Emanzipation in Familien, in denen oft ein strenges Patriarchat vorherrschte, von größter Bedeutung, in der Gründung von regelmäßigen Zusammenkünften und in Salons eine Spielfläche zu schaffen, die sie weithin in der damaligen Gesellschaft sichtbar machte. So eröffneten sich neue Formen eines Zusammenlebens, welches bis zu diesem Zeitpunkt von den starren Schranken einer im Grunde überkommenen Ständeordnung charakterisiert gewesen war.

Wenn sich die gesamtgesellschaftlichen Rahmenbedingungen am Übergang von der Spätaufklärung zur Romantik in Preußen auch geändert hatten, so erwiesen sich die einmal geschaffenen Strukturen und vor allem Rahels Netzwerk an Korrespondenten doch als so beharrlich, dass eine gewisse Kontinuität unter veränderten politischen Vorzeichen gewährleistet schien. Insofern bildete der Salon für Rahel Levin wie Rahel Varnhagen die unschätzbare Möglichkeit, aus den traditionellen Rollenerwartungen an die Frau wie an die Jüdin zu entfliehen und sich nach dem Tode des patriarchalischen Vaters nicht von ihren Brüdern rasch verheiraten zu lassen - wie ihre Schwester Rose. Neue Formen von Soziabilität wie die Salons waren das entscheidende Mittel zu einer Sprengung nicht nur überkommener Gesellschafts-, sondern auch Geschlechterordnungen; und gegen beide begehrte Rahel auf. Neue Formen von Intimität, von Freundschaft und Liebe boten Selbstverwirklichungsmodi an, die gerade für jüdische Frauen, die in der preußischen Gesellschaft doppelt marginalisiert waren, als höchst attraktiv und erstrebenswert erschienen.

Wenn Germaine de Staël ${ }^{30}$ bei ihrem Besuch der deutschen Salons den Eindruck hatte, man könne hier wesentlich unhierarchischer als in Frankreich zwischen den Ständen kommunizieren und selbst mit der Königsfamilie leicht in Kontakt kommen, so ließe sich diese Beobachtung auch auf die Normen wie die Formen der Geschlechterverhältnisse und vor allem auch der Liebeskonzeptionen übertragen. Für Rahel bot sich hier ein weites Experimentierfeld, von dem sie sehr

28 Vgl. Danzer, Gerhard: Europa, deine Frauen: Beiträge zu einer weiblichen Kulturgeschichte. Berlin - Heidelberg: Springer 2015, S. 59.

29 Vgl. Benhabib, Seyla: The Pariah and Her Shadow: Hannah Arendt's Biography of Rahel Varnhagen, S. 94.

30 Vgl. hierzu ebda., S. 97. 
bewusst Gebrauch machte. Doch diese Offenheit der Beziehungen, die Madame de Staël bei ihren Deutschlandaufenthalten noch beeindruckt hatte, verflog sehr rasch und machte restaurativen, noch stärker patriarchalischen und reaktionären Gesellschaftsstrukturen Platz.

Wenn Hannah Arendt die Entwicklung der Rahel Levin Varnhagen von der Parvenue zur Paria sich erstrecken sah, ${ }^{31}$ so gab sie - nicht ohne autobiographische Emphase - dem Spannungsfeld zwischen beiden Polen gerade mit Blick auf die Situation jüdischer Frauen in der Berliner Gesellschaft eine große Bedeutung. In der entstandenen preußischen Kastengesellschaft war Rahel zweifellos eine Paria - allerdings eine, die sich gegen Patrioten wie Patriarchen zu wehren wusste. Vielleicht markieren die Begrifflichkeiten von Parvenue und Paria gerade das Spielfeld, das den marginalisierten jüdischen Frauen blieb, um ihre Visibilität zu steigern und nicht-traditionelle Lebensformen zu entwickeln. In jedem Falle bot sich ihnen hier die Möglichkeit, ihr Schicksal beherzt in die eigenen Hände zu nehmen. Rahels Leben ist außergewöhnlich, zeigt aber die Möglichkeiten jener Epoche sehr gut auf.

Wie keine andere vermochte es Rahel Levin Varnhagen, diese Spielräume nicht nur auszuloten, sondern für sich selbst nutzbar zu machen und sich zugleich ein hohes nationales wie internationales Renommee zu erarbeiten. Wenn Rahel auf Grundlage der Rezeptionszeugnisse, wie sie im Varnhagen-Nachlass der Krakauer Jagiellonen-Bibliothek aufbewahrt werden, in einer neueren Studie als „contemporary superstar“32 bezeichnet werden konnte, so gibt dies einen Einblick in die Internationalität der Rezeptions- und Wirkungsgeschichte der Jüdin und einen Eindruck von dem, wie sie zum Teil bereits von ihren Zeitgenossen wahrgenommen wurde. Rahel Levin Varnhagen wurde keineswegs nur als vorübergehender Mittelpunkt eines von ihr geführten Salons gesehen: Gerade auch in Frankreich schrieb man ihr wichtige ideengeschichtliche und philosophische Funktionen zu. Wie Germaine de Staël war sie ein lebendiges Exempel für die Wirkungsmöglichkeiten einer auf Emanzipation drängenden Frau.

Wenn Rahel als große Figur der europäischen Ideengeschichte sowie der deutschen Romantik wahrgenommen werden konnte, so ist dies nicht denkbar ohne ihre schriftlichen Zeugnisse, ihre Tagebucheinträge und Aphorismen, aber vor allem auch ihre bis heute faszinierenden Briefe. Die Vielzahl an sehr unterschiedlichen Briefpartnerinnen und Briefpartnern zeigt, dass sie zum einen

31 Vgl. hierzu Ette, Ottmar: ÜberLebenswissen. Die Aufgabe der Philologie, S. 185.

32 Vgl. Fuchs, Renata: „Soll ein Weib wohl Bücher schreiben; Oder soll sie’s lassen bleiben?“: The Immediate Reception of Rahel Levin Varnhagen as a Public Figure. In: Neophilologus XCVIII,2 (April 2014), S. 303. Dieselbe Formulierung „contemporary superstar“ wird mit Blick auf Rahels Wirkung im Ausland bemüht (S. 309). 
die Korrespondenz in gewisser Weise als eine Art Verlängerung ihrer Tätigkeit als Salonière verstand und das mündliche Gespräch mit einer Persönlichkeit ihres Salons nun in schriftlicher Form fortsetzen und verlängern wollte. Es zeigt zugleich aber auch und vor allem, dass sie einen zweiten Freundes- und Bekanntenkreis in schriftlicher Form pflegte, der es ihr gestattete, weit über die räumlichen und zeitlichen Grenzen der unmittelbaren Face-to-face-Kommunikation hinauszugehen und so einen enormen Einfluss auf die literarisch-künstlerische Szene ihrer Zeit auszuüben.

Im Herzen von Rahel Levin Varnhagens Leben und Lebenswerk stand schlicht die Kommunikation in all ihren verschiedenartigen Formen. Sie war es, die ihr Leben immer wieder antrieb und beflügelte, ihm einen Sinn gab. Die unterschiedlichsten Formen der Soziabilität, die sie in ihren Salons pflegte, waren verknüpft mit jener lebendigen, impulsreichen und an überraschenden Wendungen reichen Korrespondenz, die uns gewiss ein Gefühl für die Lebendigkeit ihrer mündlichen Konversation innerhalb des Salons wie außerhalb zu geben vermag. Konversation und Korrespondenz bildeten die Pfeiler einer die Grenzen von Stand, Geschlecht, Beruf und Religion überspannenden Kommunikation, die auf eine Gemeinschaft zielte, welche einen unbezweifelbar politischen Anspruch besaß. Dies schloss Körperpolitiken - wie etwa die damals diskutierte Frage des Schicksals vergewaltigter Frauen - ebenso mit ein wie politische Fragen religiöser Identitätsbildung oder bezüglich des Zugangs breiter Bevölkerungsschichten zur Bildung. In einem weiter verstandenen Sinne war Politik ihre Domäne, nicht nur mit Blick auf eine saint-simonistische Ideenwelt: Rahels Ziel war ein Zusammenleben, eine grundlegende Konvivenz, die in ihrem Kern die Fundamente einer neuen, anderen Gesellschaft legen sollte.

Rahel Levin Varnhagen erprobte auf diese Weise und mit den innovativen, zum Teil auch ihre Zeitgenossen schockierenden Mitteln ihrer Epoche ein Mobile Preußens, in welchem ihre verschiedenen Figuren zu Bestandteilen jener Konfigurationen wurden, die für Preußen andere Formen und Normen der Konvivenz, des Zusammenlebens und der Partizipation entwarfen. Weit über Preußen hinaus besaß ihre Vision - ganz wie bei Germaine de Staël - eine europäische Dimension. In den Wirren einer Gesellschaft, die sich auf den Weg des Nationalismus, des Antijudaismus und Antisemitismus, der Ständeprivilegien und Geschlechterhierarchien machte, musste ihr Vorhaben scheitern. Gewiss wurde ihre Vision zu einer zeitweise verschütteten Tradition deutscher und europäischer Geistes- und Ideengeschichte, bildete aber ebenso wie das Vorhaben der Madame de Staël die Grundlage einer Entwicklung hin zu einer anderen, besseren Gesellschaft im europäischen Maßstab. Denn entgegen aller Nationalismen zeigte sie wie die Autorin von De l'Allemagne, dass ein offenes, grenzüberschreitendes Denken möglich war, innerhalb dessen auch die jüdischen Traditionen integriert werden konnten. 
Germaine de Staël hatte zweifellos gute Gründe und gute Quellen, um ihre Europa-Vorstellungen auch historisch $\mathrm{zu}$ fundieren und unter anderem ein Mittelalterbild zu propagieren, das die Zusammengehörigkeit Europas demonstrierte. In der Tat ist die Umwertung des Mittelalters - wie wir ja schon bei Chateaubriand sahen - ein wesentliches Element, aus dem sich das romantische „imaginaire“ nährt. Doch es gab auch konkrete Texte, die Germaine de Staël aus dem deutschsprachigen Kontext sehr gut kannte und wie Rahel Levin Varnhagen im Anschluss etwa an Goethe einzuordnen wusste. Es sind Texte, die ein verändertes, keineswegs mehr ,dunkles‘ Mittelalter propagierten und nicht mehr in der Renaissance, sondern in ihm die Grundlage einer Entwicklung Europas im Zeichen des Christentums erblickten.

Germaine de Staël, die ein umfassendes Europabild im Auge hatte, wie es schon zu Beginn von De l'Allemagne aufschien, interessierte sich in einem ganz besonderen Maße für jene Schrift des Novalis oder Friedrich von Hardenberg, die den Titel Die Christenheit oder Europa trug und aus dem Jahr 1799 stammte. Zum gleichen Zeitpunkt wie bei Chateaubriand stoßen wir auf eine Neubewertung des Christentums; bei Novalis allerdings nicht aus tendenziell panlateinischer Perspektive, sondern mit germanischen Untertönen. Erinnert sei an dieser Stelle lediglich an den ersten Satz dieser Schrift: „Es waren schöne, glänzende Zeiten, wo Europa ein christliches Land war, wo Eine Christenheit diesen menschlich gestalteten Welttheil bewohnte.“33

Bereits in diesem literarischen Auftakt lässt sich unverkennbar Novalis’ Ausrichtung an einer scheinbar längst abgestreiften vergangenen Epoche und mehr noch an der vergangenen Einheit eines christlichen Europa erkennen. Es sind nicht die Auseinandersetzungen, Kämpfe und Kriege zwischen den verschiedenen christlichen Reichen, die im Mittelpunkt dieses Bildes stehen, sondern die Fiktion einer Einheit, welche jenseits des Christentums längst wieder zerfallen sei.

Daraus ließe sich die Folgerung ableiten, dass es sich beim romantischen Diskurs um einen nach Einheit strebenden, stets Homogenität suchenden und das Fremde aussperrenden Diskurs des Eigenen und Eigentlichen handle. Dass mit dieser religiös akzentuierten abendländisch-christlichen Einheit zugleich eine Abwertung all dessen einherging, was die Aufklärung ins Spiel gebracht hatte, ist offenkundig: Der Mensch habe seinen christlichen Glauben und damit seine transzendente Anbindung, seine Mitte verloren. Diese gelte es jetzt wieder zu gewinnen!

33 Novalis: Die Christenheit oder Europa. In Tieck, Ludwig / Schlegel, Friedrich (Hg.): Novalis. Schriften. Band I. Berlin: Reimer 1826, S. 187-208, hier S. 189. 
Eine solche Sichtweise hat sicherlich viel für sich, kollidiert allerdings mit dem in unserer Vorlesung über das 18. Jahrhundert erarbeiteten Befund, demzufolge die interkulturelle Auseinandersetzung keineswegs in der Spätaufklärung zu einem Halt kam. Gewiss wurde diese Auseinandersetzung von anderen, vordringlicher scheinenden Fragen in den Hintergrund gedrängt. Doch hatte sich seit der napoleonischen Besetzung Preußens und der ,Flurbereinigung، der deutschen Länder durch Frankreich der Wind gedreht: Ein neues Denken verschaffte sich Raum, das immer deutlicher angesichts der Schwäche der deutschen Kleinstaaterei zur nationalen Stärke aufrief und die alte, unter französischer Vorherrschaft stehende, paneuropäische „République des Lettres“ der Aufklärungszeit aufkündigte.

Ein gutes Beispiel für diesen Sinneswandel ist Johann Gottlieb Fichte, mit dem Madame de Staël in Berlin direkten Kontakt aufgenommen hatte. In seiner kosmopolitischen Phase ${ }^{34}$ hatte er noch äußerst weltoffene Thesen vertreten, die etwas von jenem Geist universalen Denkens atmeten, auf den die Staël bei den deutschen Denkern vielleicht ein wenig spöttisch hingewiesen hatte, könne man in der deutschen Philosophie doch nur über das Universum arbeiten oder habe nichts zu tun. Nun aber sprach sich in ihm eine klare, sicherlich für den deutschsprachigen Raum unter dem Einfluss napoleonischer Expansionspolitik verallgemeinerbare Tendenz zur Suche nach einer absoluten Homogenität des Eigenen, des ,Deutschen“ aus. Nun wurde von ihm eine Überlegenheit des deutschen Geistes nicht nur abstrakt behauptet; vielmehr wurden Gründe dafür in der allgemeinen Sprachentwicklung angeführt. Lassen Sie mich an dieser Stelle kurz darauf hinweisen, dass Sprache, Sprachentwicklung und deren Studium in der Philologie des 19. Jahrhunderts zu Dreh- und Angelpunkten für einen entstehenden und ,wissenschaftlich' begründeten Rassismus wurden, dem wir am Lehrstuhl mit einer von Markus Messling geleiteten Emmy-Noether-Forschergruppe, welcher Markus Alexander Lenz und Philipp Krämer angehörten, nachgegangen sind. ${ }^{35}$ Die wichtigen Ergebnisse dieser Gruppe kann ich freilich hier nicht darstellen, sondern nur vereinzelt in diese Vorlesung einfließen lassen.

34 Vgl. hierzu Jurt, Joseph: Sprache, Literatur, Nation, Kosmopolitismus, Internationalismus. Historische Bedingungen des deutsch-französischen Kulturaustausches. In: Dorion, Gilles / Meißner, Franz-Joseph / Riesz, János / Wielandt, Ulf (Hg.): Le français aujourd'hui. Une langue à comprendre. Französisch heute. Mélanges offerts à Jürgen Olbert. Frankfurt am Main: Verlag Moritz Diesterweg 1992, S. 230-241; sowie besonders Kleingeld, Pauline: Six Varieties of Cosmopolitanism in Late Eighteenth-Century Germany. In: Journal of the History of Ideas (Baltimore) LX, 3 (July 1999), S. 505-524.

35 Verwiesen sei auf die Publikationen dieser fruchtbaren Gruppe, u. a. die Potsdamer Habilitationsschrift von Messling, Markus: Gebeugter Geist. Rassismus und Erkenntnis in der modernen 
Wenden wir uns folglich kurz einem Auszug aus Johann Gottlieb Fichtes Reden an die deutsche Nation $\mathrm{zu}$, welche nach seiner ,Wende“ entstanden: Die Deutschen hätten als ein germanisches Volk anders als die nach Frankreich oder Spanien weitergezogenen Stämme nicht ihre germanische Sprache aufgegeben, wie dies bei den latinisierten Völkern der Fall gewesen sei! Sie merken, dass sich bei Fichte eine auf den ersten Blick mit Germaine de Staël vergleichbare Einteilung der verschiedenen europäischen Völker findet, nur mit einer völlig anderen, wenn auch nicht diametral entgegengesetzten Bewertung. So lässt sich in De l'Allemagne zweifellos die Spur der deutschen Philosophie nicht weniger als jene der deutschen Literatur nachweisen - Doch wir haben uns lange genug mit De l'Allemagne beschäftigt! Gestatten Sie mir also, an dieser Stelle nun nicht etwa Madame de Staëls Deutung der deutschen Philosophie und insbesondere des deutschen Idealismus vorzutragen, sondern diese Philosophie und Ästhetik selbst zu Wort kommen zu lassen:

Die Verschiedenheit ist sogleich bei der ersten Trennung des gemeinschaftlichen Stamms entstanden und besteht darin, dass der Deutsche eine bis zu ihrem ersten Ausströmen aus der Naturkraft lebendige Sprache redet, die übrigen germanischen Stämme eine nur auf der Oberfläche sich regende, in der Wurzel aber tote Sprache. ${ }^{36}$

In dieser Passage zeigt sich nun anders als bei Germaine de Staël eine klare und deutliche Wertigkeit, eine positive Wertung der Deutschen als ihrer Herkunft treuen Germanen, verbunden mit einer Abwertung aller anderen, welche sozusagen vom ,rechten' Wege abgewichen sind. Diese durchaus ,völkischen' Vorstellungen wurden später - wofür der arme Fichte nichts konnte - nicht nur von den Nationalsozialisten vor ihren Karren gespannt, sie enthalten auch eine Vielzahl von Vorstellungen, die über einen langen Zeitraum in die Sprachpsychologie und die Sichtweise der Sprachen in Deutschland eingegangen sind. Noch in der Abwertung der romanischen Sprachen durch Rudolf Steiner, also in den des Nazitums unverdächtigen Bildungskonzepten der Anthroposophie und ihrer Ablehnung der vom Lateinischen sich herleitenden Sprachen und Völker als dekadent, können sie derartige Vorstellungen wiederfinden. Letztere wurden im weiteren

europäischen Philologie. Göttingen: Wallstein Verlag 2016; sowie die mit „summa“ bewertete Dissertation von Lenz, Markus Alexander: Genie und Blut. Rassedenken in der italienischen Philologie des neunzehnten Jahrhunderts. Paderborn: Wilhelm Fink Verlag 2014; sowie die Akten einer internationalen Tagung von Messling, Markus / Ette, Ottmar (Hg.): Wort Macht Stamm. Rassismus und Determinismus in der Philologie (18. / 19. Jh.). Unter Mitarbeit von Philipp Krämer und Markus A. Lenz. München: Wilhelm Fink Verlag 2013.

36 Fichte, Johann Gottlieb: Reden an die deutsche Nation. Berlin: Realschulbuchhandlung 1808, S. 140 . 


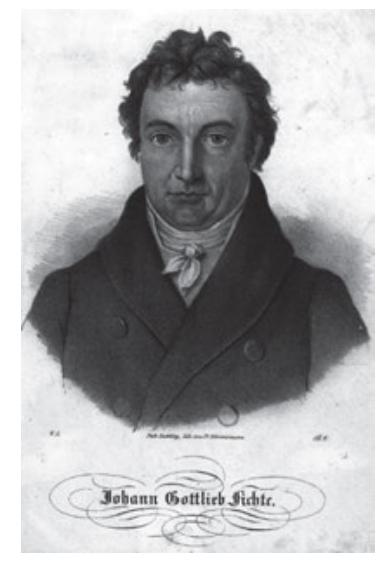

Abb. 46: Johann Gottlieb Fichte (Rammenau, Kurfürstentum Sachsen, 1762 - Berlin, 1814).

Verlauf des 19. Jahrhunderts noch durch die kriegerischen Erfolge der, germanischen Völker' gegen Frankreich weiter verstärkt, was nicht allein einer riesigen germanischen Mythologie dieses Jahrhunderts und einer Aufwertung alles ,Germanischen', sondern auch bestimmten, um den Bestand und die Pflege dieses kulturellen Erbes besorgten wissenschaftlichen Disziplinen ein unverbrüchliches Existenzrecht einräumte.

Die völkischen Fiktionen von Johann Gottlieb Fichte hatten einen nachhaltigen Erfolg und entwarfen das Bild einer germanischen (und damit letztlich ,rassischen') Einheit und Homogenität, das bis zum heutigen Tag in Krisenzeiten wie auch in den unsrigen nach dem Ende der vierten Phase beschleunigter Globalisierung immer wieder gerne angerufen wird. Es ist - wenn Sie mir den Ausdruck gestatten - eine Einheit, die auf einer vermeintlichen Reinheit gründet. Damit aber bildet sie ein Argumentationsschema, das diskursanalytisch betrachtet nicht nur völlig idealistisch und kulturfremd ist: Die Grundpfeiler dieses Schemas oder genauer germanisch-völkisch-nationalen Diskurses spuken bis heute in den seltsamsten Varianten durch die Hirne von Menschen, welche von einem klaren, reinen Deutschtum faseln, das verteidigt werden müsse. Dass in ein solches Deutschtum weder Franzosen noch Juden hineinpassten, lag schon zeitgenössisch auf der Hand - und nicht nur eine Rahel Levin Varnhagen bekam es zu spüren.

Dabei besteht eine Beziehung zu Fichtes Begriff vom Subjekt, wie er dies in seiner Schrift Über den Begriff der Wissenschaftslehre oder der sogenannten Philosophie pointiert zum Ausdruck brachte. Denn das Subjekt ist für Fichte gleichsam ein absolut gesetztes Subjekt, das aus sich heraus besteht und seinen Grund in sich selbst hat, eine Absolut-Setzung des Idealistischen, die selbstverständlich wieder von einer Einheit und Reinheit ausgeht und zur Grundlage eines absolu- 
ten, also von allem Empirischen losgelösten Handelns wird. Wie sieht diese Definition aus?

Das Ich setzt sich selbst, und es ist, vermöge dieses blossen Setzens durch sich selbst; und umgekehrt: das Ich ist, und es setzt sein Seyn, vermöge seines blossen Seyns. - Es ist zugleich das Handelnde, und das Product der Handlung; das Thätige, und das, was durch die Thätigkeit hervorgebracht wird; Handlung und That sind Eins und ebendasselbe; und daher ist das: Ich bin, Ausdruck einer Thathandlung; aber auch der einzig-möglichen, wie sich aus der ganzen Wissenschaftslehre ergeben muss. [...] Alles, was ist, ist nur insofern, als es im Ich gesetzt ist, und ausser dem Ich ist nichts. ${ }^{37}$

Wir haben es hier fraglos mit einem absoluten Glauben an das (idealistische) Subjekt zu tun, welcher zugleich das Objekt als ein Entgegen-Stehendes, als einen Gegen-Stand, ausschließt und dem Subjekt allein Tat und Tatkraft überantwortet. Man könnte hier von einer Maßlosigkeit dieses Fichte'schen Ich, dieses Fichte'schen Geistes sprechen, wobei jegliche Form von Ob-Jektivität, ja von Alterität, von Anders-Artigkeit, im Angesicht dieses Ich beiseite geräumt wird. Angesichts dieser Absolut-Setzung von Ich und Geist fallen einem wieder die mahnenden Worte der Germaine de Staël zur deutschen Philosophie ein, die von keiner Einbettung in eine umfassendere Soziabilität gezügelt scheint; oder auch die Worte des argentinischen Schriftstellers Jorge Luis Borges, der gerade mit Blick auf die deutsche Philosophie von den großen fiktionalen Entwürfen sprach. Die Ergebnisse dieses Denkens griffen freilich - wie in Tlön, Uqbar, Orbis Tertius ${ }^{38}$ - in die Wirklichkeit ein und transformierten sie grundlegend.

Wenn ich Johann Gottlieb Fichte hier gewählt habe, dann nicht, um etwa gegenüber der weltoffenen Schweizerin einen Deutschen zu zitieren, der Deutschland über alles hebt. Wir sollten über dem Fichte der Reden an die deutsche Nation nicht den kosmopolitischen Fichte vergessen, der sehr wohl etwas beitrug zu jener Verständigung zwischen unterschiedlichen Völkern und Kulturen, welche in der zweiten Phase beschleunigter Globalisierung im Verlauf der zweiten Hälfte des 18. Jahrhunderts entstanden war. ${ }^{39}$ Deutschland, die deutsche Literatur oder die deutsche Philosophie stehen keineswegs für eine engstirnige Auslegung interkultureller Beziehungen, sondern haben - und dafür war uns Heinrich von Kleist ein erstes Beispiel gewesen - wesentlich an der kon-

37 Fichte, Johann Gottlieb: Über den Begriff der Wissenschaftslehre oder der sogenannten Philosophie. Zweite verbesserte und vermehrte Ausgabe. Jena - Leipzig: Bei Christian Ernst Gabler 1798, S. 95-98.

38 Vgl. hierzu Band 3 der Reihe „Aula“, also Ette, Ottmar: Von den historischen Avantgarden bis nach der Postmoderne, S. 494-548.

39 Vgl. hierzu Band 1 der Reihe „Aula“, also Ette, Ottmar: ReiseSchreiben (2020). 
zeptionellen Ausgestaltung von Beziehungen zwischen unterschiedlichen Kulturen mitgearbeitet. Es zeigt sich in dem in diesen Argumentationen beleuchteten Zusammenhang aber, dass der romantische Diskurs äußerster Spannung ausgesetzt war, dass - mit anderen Worten - der Diskurs der Romantik in einen brandgefährlichen Gegensatz eingespannt war, der in der Tat auch die weitere politische Geschichte des 19. Jahrhunderts entscheidend mitprägen sollte. Dies bedeutet nicht, den romantischen Chateaubriand zu einem Erzreaktionär und den romantischen Fichte zu einem Vorläufer der Nationalsozialisten zu erklären, wohl aber, eine ,Dialektik der Romantik‘ mitzudenken, wie sie die vor den Nazis geflohenen Horkheimer und Adorno in ihrer Dialektik der Aufklärung entfalteten.

Nun ist die Sehnsucht nach Einheit nach homogener Reinheit, ein Grundzug, der gerade Deutschland und eine spezifisch deutsche Variante der Romantik oder - allgemeiner noch - überhaupt der Moderne geprägt hat. Diese Sehnsucht mag sich gewiss auch im Politischen, in Form der jahrzehntelangen Suche nach dem einen Nationalstaat äußern. Sie findet sich aber von Beginn an im Umfeld der Kritik an den Grundlagen und mehr noch an den Ergebnissen eines analytischen Denkens, wie es die europäische Aufklärung repräsentierte. Denn Analyse ist letztlich immer Scheidekunst: Sie setzt die Dinge auseinander, aus-einander, und ist nicht so sehr an deren Zusammensetzung als an einer fortgesetzten Aufspaltung zur weiteren Analyse interessiert.

Wenn aber alles analysiert werden kann, so lässt sich auch alles aufspalten. Die Synthese muss daher aus einer solchen Sicht notwendig die Analyse komplettieren, vielleicht sogar dialektisch an ihre Stelle treten, um eine durch die Analysetätigkeit der Aufklärung in Atome zersplitterte Welt als Ganzes wiederherstellen zu können. Zwei Wege, die eng miteinander verbunden sind, treten hier auf den Plan und lassen sich voneinander unterscheiden: die Kunst und die Mythologie oder - wie wir auch mit Manfred Frank sagen könnten - die „Neue Mythologie“. ${ }^{40}$

Diese „Neue Mythologie“ kann wieder an die Stelle der alten Religion als einheitsstiftende Kraft treten, wenn es ihr denn gelingt, die Einheit einer Vorstellungswelt zu stiften, welche durch die Aufklärung zuvor in tausend Bruchstücke geborsten war. Gerade in Deutschland wurde die Notwendigkeit, eine solche neue Einheit, eine solche neue Mythologie zu schaffen, wie in kaum einem anderen Lande Europas entworfen und entwickelt. Die Kunst - und gerade auch die Poesie - besitzt die vordringliche Aufgabe, zu einer allgemeinen Symbolik zurückzufinden, wie Georg Friedrich Wilhelm Hegel dies formulierte.

40 Vgl. Frank, Manfred: Der kommende Gott. Vorlesungen über die Neue Mythologie. 1. Teil. Frankfurt am Main: Suhrkamp 1982. 
Im Kontext der deutschen Naturphilosophie - dies deutete sich bereits bei Madame de Staël in der oben angeführten Stelle an - müssen wir nicht lange nach Begründungen suchen. Denn In Friedrich Wilhelm Schellings Würzburger Vorlesung von 1804 wurde die Motivation der Forderung nach einer neuen Mythologie - wie Manfred Frank betonte ${ }^{41}$ - mit seltener Klarheit vorgetragen:

Stoff der Kunst ist jeder mögliche Gegenstand nur durch die Kunst also nicht getrennt von der Form. Form und Stoff sind in der Kunst ebenso wie im Organismus eins. Dieß erhellt am deutlichsten aus dem Verhältnis der Poesie und Kunst [...]. Die Wiedergeburt einer symbolischen Ansicht der Natur wäre daher der erste Schritt zur Wiederherstellung einer wahren Mythologie. Aber, wie soll diese sich bilden, wenn nicht zuvörderst eine sittliche Totalität, ein Volk sich selbst wieder als Individuum constituirt hat? Denn die Mythologie ist nicht Sache des Individuums oder eines Geschlechts, sondern nur eines Geschlechts, das von Einem Kunsttrieb ergriffen und beseelt ist. Also weist uns die Möglichkeit einer Mythologie selbst auf etwas Höheres hinaus, auf das Wiedereinswerden der Menschheit, es sey im Ganzen oder im Einzelnen. So lange ist nur partielle Mythologie möglich, die aus dem Stoff der Zeit, wie bei Dante, Shakespeare, Cervantes, Goethe, aber keine universelle, allgemein symbolische. [...] Die Frage nach der Möglichkeit eines universellen Stoffs der Poesie, ebenso wie die Frage nach der objektiven Existenz der Wissenschaft und der Religion, treibt uns also von selbst auf etwas Höheres hin. Nur aus der geistigen Einheit eines Volks, aus einem wahrhaft öffentlichen Leben, kann die wahre und allgemeingültige Poesie sich erheben - wie nur in der geistigen und politischen Einheit eines Volks Wissenschaft und Religion ihre Objektivität finden. ${ }^{42}$

In diesen prägnanten Worten Schellings, der wie kaum ein anderer deutscher Philosoph den Weg des deutschen Idealismus in die Romantik prägte, der eine Naturphilosophie entfaltete, welcher Humboldt anfänglich viel abzugewinnen wusste, dann aber zunehmend den exakten Wissenschaften den Rücken kehrte und sich im Sinne Manfred Franks einer Herausbildung der Neuen Mythologie zuwandte, wird deutlich, welches einige der tieferen Ursachen für den Wunsch nach einer Wiedergewinnung der Einheit gerade in Deutschland sind. Auch für Schelling steht die wiederzugewinnende Einheit - des Volks, der Identität, des Weltbilds - dabei im Zentrum, wobei der Kunst und insbesondere der Poesie eine entscheidende Funktion zufällt.

Wir werden bald am Beispiel von Giacomo Leopardi sehen, wie sehr dies ein Problem war, das keineswegs nur die deutschen Geister beschäftigte. Es handelte sich vielmehr um eine Grundfrage des modernen Subjekts, das aus der

41 Vgl. ebda., S. 198.

42 Schelling, Friedrich Wilhelm: Würzburger Vorlesung. In: Sämtliche Werke. Erste Abtheilung, Band 6 [1804]. Stuttgart und Augsburg: J. G. Cotta'scher Verlag 1860 S. 572 f. 
alten, transzendent verankerten Gesellschaft in eine immer stärker zersplitterte und desakralisierte entlassen worden war. Diesem modernen Subjekt wurde nun aufgetragen, sich als Mensch innerhalb dieser Gesellschaft einen eigenen Platz, einen eigenen Ort zu suchen - und damit auch eine neue Bestimmung. Diese Suche nach einer verlorenen Einheit und damit letztlich auch die Suche nach übergeordneten Werten sowie nach einer Gemeinschaft, in der diese übergeordneten Werte Gültigkeit besitzen oder zumindest beanspruchen sollten, war eine der gleichsam metaphysischen Triebfedern der Romantik im Allgemeinen und der deutschen Romantik im Besonderen. Diese Konstellation im Sinne einer verlorenen Einheit und Einigkeit wirkte sicherlich noch drängender in einem Gewirr von Einzelstaaten, die nach ihrer politischen Einheit suchten, beschränkte sich aber keineswegs auf den deutschsprachigen Raum.

Als einen möglichen Übergang zur später sich anschließenden kurzen Untersuchung der Lyrik Giacomo Leopardis möchte ich Ihnen an dieser Stelle den Blick in ein Buch vorschlagen, das vom französischen Literaturwissenschaftler Albert Béguin, der längere Zeit in Deutschland als Lektor gearbeitet hatte, erstmals im Jahr 1937 vorgelegt und dann in einer überarbeiteten Ausgabe 1938 definitiv veröffentlicht wurde. Albert Béguin darf als einer der für das 20. Jahrhundert wichtigsten Vermittler zwischen Deutschland und Frankreich gelten. Die Tragik dieser fruchtbaren Vermittlung mag sicherlich darin liegen, dass sie von der Zeitgeschichte, vom Aufstieg, Triumph, der immensen Niedertracht und barbarischen Grausamkeit des Nationalsozialismus sowie den Horrorvisionen des Zweiten Weltkriegs und der Shoah verschüttet wurde.

Das Thema der Studie von Albert Béguin war der Zusammenhang zwischen der romantischen Seele mit dem Traum und damit letztlich mit der Frage nach jenem Bereich, der von der Aufklärung ausgeschlossen wurde, dem sich nun aber die Romantiker entschlossen zuwandten und damit zu einer Art Vorläufer der Surrealisten wurden. ${ }^{43}$ Wir hatten bereits mehrfach das ,je ne sais quoi“ als Indiz für diesen Übergang zur Einbeziehung des Irrationalen in die Literatur bemerkt; und der Traum stand für das Andere, das Irrationale, das nicht unmittelbar in eine Analyse zu bringen war. Er konnte vielmehr wie das Kunstwerk im Lichte einer Synthese oder gar als Ergebnis einer Synthese erscheinen - und eben hierin lag eine der großen Herausforderungen der romantischen Epoche.

Ich möchte Ihnen gerne aus dem letzten Kapitel von Béguins Buch L'âme romantique et le rêve, dieser Studie über die romantische Seele und den Traum einen kleinen Auszug präsentieren. Mit Hilfe der nachfolgenden Passage möchte

43 Vgl. hierzu Band 3 der Reihe „Aula“ von Ette, Ottmar: Von den historischen Avantgarden bis nach der Postmoderne, S. 336-398. 
ich erneut auf eine Beziehung zur verlorenen Einheit, zur Dimension des Absoluten, des Unendlichen und der Synthese in einer Welt, die zugleich auch die Welt des Ich, die Traumwelt des absoluten Subjekts ist, hinweisen und aufmerksam machen:

Ein vages Bedauern warnt den modernen Menschen davor, dass er mit der Welt, in die er hineingestellt ist, vielleicht tiefere und harmonischere Beziehungen gehabt hat oder haben könnte. Er weiß sehr wohl, dass es in ihm selbst Möglichkeiten des Glückes oder der Größe gibt, von denen er sich abgewandt hat. [...] Die Idee der universellen Analogie, auf welche sich die romantische und die moderne Konzeption der Dichtkunst beziehen, bildet die Antwort des menschlichen Geistes auf die Frage, die er sich stellt, und den Ausdruck seines tiefsten Wunsches. Er hat sich ersehnt, der Zeit und der Welt der verschiedenartigsten Erscheinungen zu entkommen, um das Absolute und die Einheit zu fassen. Die Kette der Analogien erscheint ihm bisweilen wie das Band, welches alle Dinge mit allen anderen verbinde, auf diese Weise das Unendliche durchläuft und die unauflösliche Kohäsion des Seins erzeugt.

Von diesem Gesichtspunkt aus gesehen, nimmt der Mythos vom Traum eine neue Bedeutsamkeit an. Das Träumen ist nicht mehr nur eine der Phasen unseres Lebens, in welcher wir uns im Austausch mit der tiefen Realität wiederfinden. Der Traum ist weit mehr als das kostbare Modell der ästhetischen Schöpfung, und man begnügt sich nicht länger damit, seine unzähligen spontanen Metaphern aufzunehmen, mit deren Hilfe das träumende Genie voneinander durch die Zeit getrennte Momente sowie voneinander im Raum distante Wesen und Gegenstände miteinander in Beziehung setzt. Der Traum und die Nacht werden zu den Symbolen, mit deren Hilfe ein Geist, welcher die Welt des Scheins zu verlassen und sich mit dem Sein zu verbinden wünscht, die Vernichtung der fühlbaren Welt zum Ausdruck zu bringen sucht. ${ }^{44}$

Das Streben nach Einheit und Verschmelzung verwirklicht sich für die Romantiker gleichsam auf der Nachtseite der Vernunft, in der von der Vernunft nicht mehr kontrollierbaren Synthese des Traumes. Wir haben damit neben den bislang analysierten eine Reihe weiterer Elemente eingeführt, die von größter Bedeutung und Tragweite für die Romantik und den romantischen Diskurs sind. Denn im Traum konkretisieren sich die Wünsche und Ziele der Romantik: Der Traum und damit die Nachtseite der Vernunft sind der Helligkeit und dem Lichte der Aufklärung diagonal entgegengesetzt.

Fassen wir unsere Gedanken an dieser Stelle unserer Vorlesung zusammen: Die Suche nach der (verlorenen, durch die Aufklärung zerstörten) Einheit, die nicht allein ästhetische Aufwertung des Christentums und des ehedem ,dunklen“, ,finsteren' Mittelalters, der Absolutheitsanspruch eines von allem losgelösten und

44 Béguin, Albert: L'âme romantique et le rêve. Essai sur le romantisme allemand et la poésie française. Nouvelle édition. Paris: Librairie José Corti 1939, S. 397 u. 401. 
sich selbst einsetzenden Subjekts, die Sehnsucht nach einer homogenen Gemeinschaft, welche auch die völkische oder nationale Gemeinschaft sein kann, die Hoffnung auf die Wiederherstellung einer Einheit mit dem Transzendenten und jenen Elementen, die von der Aufklärung ausgeblendet wurden, gleichsam die Schattenseite und mehr noch die Nachtseite der Vernunft und rationalen Existenz - all dies konkretisiert sich in der Synthese des Traums. Die Romantik wählt mithin das Andere anders, wählt die Nacht anstelle des Lichts, wählt das Irrationale zuungunsten der Rationalität. Sie wählt nicht so sehr als ihr Anderes die anderen Kulturen, sondern zielt auf diesem Gebiet auf eine größere Homogenität, um sich von dieser veränderten Position aus dem Anderen im Ich, dem Anderen im Eigenen zuzuwenden, jener Sehnsucht nach dem nicht mehr durch Analyse Auflösbaren, einer Sehnsucht nach dem Unendlichen. Diese Sehnsucht nach dem unendlich weit Entfernten ist ein Verlangen, welches sich auch auf die Entfernung im Raum erstreckt und ein projektiertes und ersehntes Anderes in weit entfernten Weltgegenden anstrebt. 
